\title{
Building a Single Sign- On System for the Department of Homeland Security's Infrastructure Protection Gateway
}

John Motley, Isabel Hilton

July 2019

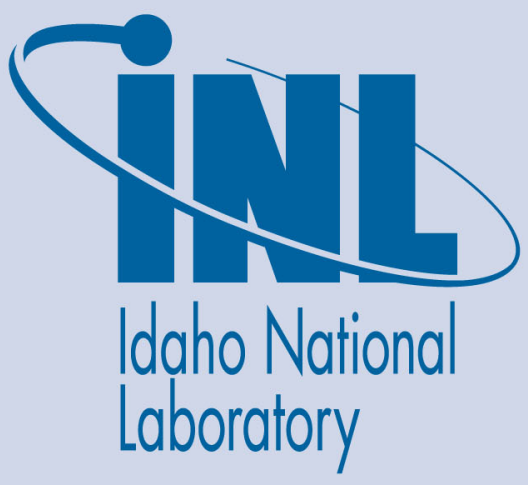

The INL is a U.S. Department of Energy National Laboratory operated by Battelle Energy Alliance 


\title{
Building a Single Sign-On System for the Department of Homeland Security's Infrastructure Protection Gateway
}

\author{
John Motley, Isabel Hilton
}

July 2019

Idaho National Laboratory Idaho Falls, Idaho 83415

http://www.inl.gov

Prepared for the U.S. Department of Energy Office of Nuclear Energy Under DOE Idaho Operations Office

Contract DE-AC07-05ID14517 


\section{Building a Single Sign-On System for the Department of Homeland Security's Infrastructure Protection Gateway}

\section{INFRASTRUCTURE PROTECTION (IP) GATEWAY}

The IP Gateway is a single interface through which Department of Homeland Security (DHS) mission partners can access a large range of integrated Office of Infrastructure Protection (IP) systems and capabilities to conduct comprehensive data collection and analysis. It enables federal, state, local, tribal, and territorial partners to manage information about the infrastructure in their communities for risk management, infrastructure protection, event planning, and incident response activities.

The IP Gateway provides a suite of situational, analysis, and assessment capabilities, resources, and data that support the execution of critical infrastructure security and resilience activities within the homeland security community.

\section{SINGLE SIGN-ON (SSO)}

\section{HISTORY}

The IP Gateway (IPG) currently depends on a third-party to authenticate and track users. When a user submits his/her login information, that information goes to a third-party source where it is stored, authenticated, and returned to the IPG. The IPG is completely dependent on this outside source. If the outside source experiences an outage, the IP Gateway does as well, and only when the thirdparty solves its problem will service to the Gateway resume.

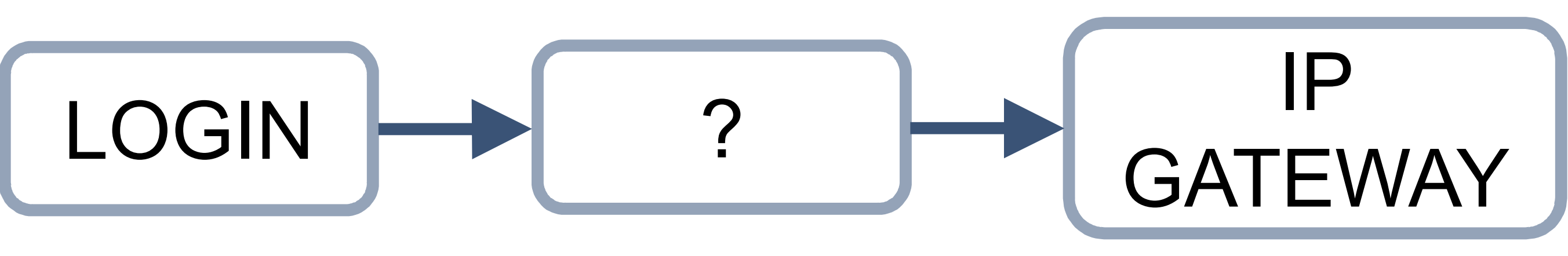

CURRENT SYSTEM: What happens between login and reaching the IP Gateway landing page is out of DHS' control.

\section{CURRENT PROJECT}

DHS wants to move away from depending on a third-party, so we built a new SSO system hosted by DHS. The SSO system validates incoming users through two-factor authentication, using passwords and either email or SMS. Once complete, the SSO system will remove third-party dependency from the IP Gateway and provide more reliability to its users.

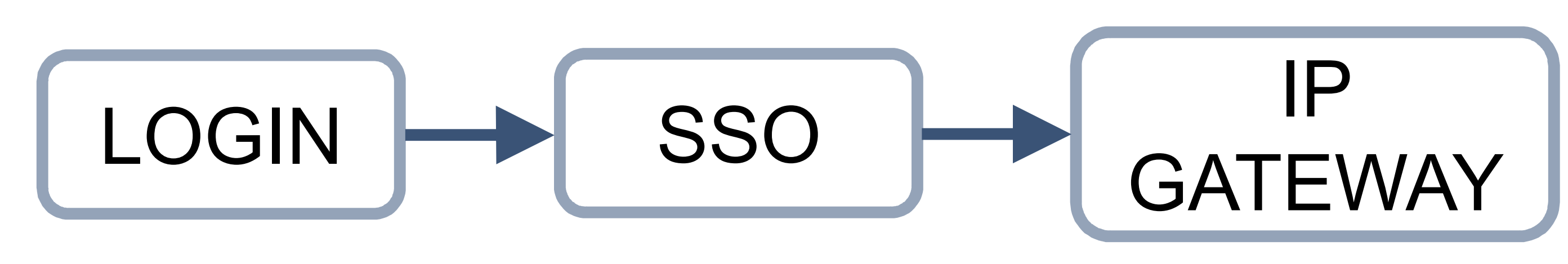

NEW SYSTEM: SSO returns complete control to DHS to better serve IP Gateway users.

\section{JOHN MOTLEY • ISU ISABEL HILTON • BYU \\ Erik Peterson} Infrastructure Assurance and Analysis 